\title{
One language, Two Perspectives: IRISH ENGLISH AND IDENTITY IN THE GLOBAL CONTEXT
}

\author{
RALUCA-GEORgIANA DEACONEASA*
}

\begin{abstract}
This paper explores the case of Irish English with an emphasis on the relationship between language and identity. Within the mosaic of World Englishes, Irish English occupies its own place, as its emergence can be considered a form of resistance from the forces of colonialism. The essay is divided into two main parts. The first section investigates irregularities in morphology and syntax with examples taken from the forms of the language spoken in Galway and Dublin, alongside external influences observed at the phonetic level. From these perspectives, the second part of the paper will further illustrate the status of the Irish language, culture, and identity within the global context, seeking to see if future generations will continue to be part of what now bears the name of Irish nation.
\end{abstract}

Keywords Identity, Irish English, Language Shift, Irish, Nationalism, Future Prospects.

\section{Introduction}

Language-related issues have a defining role when analysing the construction and development of the British Empire, as the colonized communities found themselves in unexpected unions and were often forced to use the English language. For instance, in Article 8, of Ireland's 1937 Constitution, English is recognized as the second official language. At the same time, Section 3 of the Article permits provision to be made by law for the exclusive use of Irish or English for official purposes

* Babeş-Bolyai University of Cluj-Napoca. deaconeasaraluca9@gmail.com.

DOI: 10.26424/philobib.2021.26.2.11 
"either throughout the state or in any part thereof. ${ }^{1 "}$ This marks a particularly important aspect as it frames the country not only suited to attain bilingualism, but it can point out as well the risk that the population might lean more towards the benefits and opportunities of the contemporary Anglophone culture than to its own language and heritage. Despite the numerous claims coming from the Irish people saying that Gaelic is their own language, only 5 per cent of the population used the language on a daily basis, but what is noticeable nonetheless stands in the roots of the country defined by Great Britain's colonization.

The consequences of the clash between these two rich cultures and languages can be observed in the increasing lexical pressure of English, more visible in specific communities (such as the Gaeltacht) where the Irish speakers master the English language just as well, resulting in a fusion of the two which is visible in expressions, lexical borrowings, exclamations and adverbs, or answers formulated through a combination of the given languages. In this case, Liam Mac Mathúna ${ }^{2}$ notes that, there is a tendency to use the English no and yeah/yes in a case such as: beidh tú ag goil ann? Nó ní bheidh/ ní bleidhead, meaning "you'll be going there? No, I won' $t$ ". Thus, as the shift from an Irish speaking country where more than $50 \%$ of the population spoke the language to a bilingual population has taken place, several aspects need further investigation and they are related to particularities of Irish English as a result of the country's resistance to the forces of colonialism.

Generally speaking, Ireland occupies a key point within the sea of British colonies. The country was the first British colony and in the historical spread of English to various overseas locations, Irish English, alongside Scottish English and British English, played a central role. ${ }^{3}$ Over the years it can be observed that immigration has become the dominant social concern in the Republic of Ireland fact that raises serious questions about language, as the immigrant population increased by 53 per cent between 2002 and 2006, whereas foreign-born residents accounted for 14 per cent of the population in 2006 compared with 10 per cent in $2002 .{ }^{4}$ Aside from the Asians, Africans and other people coming from western Europe, the number of immigrant children under 15 exceeded 50,000 and despite the fact that 20,000 of them came from Britain or other English-speaking countries, a considerable number (about 30,000) must have language problems. In this sense, the Government policy "rejects multiculturalism in favour of integration which is to be achieved by providing additional English-language instruction for pupils in the

\footnotetext{
${ }^{1}$ See Ireland's Constitution of 1937 with Amendments through 2012. Constitute Project, 19 February 2021, www.constituteproject.org/constitution/Ireland2012.pdf

2 See Caoilfhionn Pháidín, Seán Ó Cearnaigh, eds. A New View of the Irish Language. (Dublin: Cois Life, 2008), 84.

${ }^{3}$ Raymond Hickey, Legacies of Colonial English. Studies in Transported Dialects, (Cambridge: Cambridge UP, 2004), 82.

${ }^{4}$ See Caoilfhionn Pháidín, Seán Ó Cearnaigh, eds. A New View of the Irish Language, 226.
} 
educational system and classes for adults via the Vocational Educational Committees - through which structure adult education programmes are delivered, ${ }^{5 \prime \prime}$ therefore no matter how well the Irish language will be preserved, English language should be known by each citizen.

When analysing the significant number of emigrations, as well as immigrations it can be observed the manipulation of integration policies that continues to threaten the Irish language and cause anxiety among the citizens. Despite the fact that these policies were in accordance with international best practices and were producing high levels of literacy in English and Irish ${ }^{6}$ as an effort to undermine teaching through Irish, the need to ensure English-language literacy in the immigrant community instigated an attack coming from the Department of Education and Science on highly successful language-immersion practices in the Irish-medium schools, gaelscoileanna. In the same category is An Post which ceased to deliver letters for the Irish mail service in Dublin marked Baile Átha Cliath because of the immigrants employed in the office and in favour of the challenges faced by machines when dealing with the Irish language of Dublin. These are only two such instances enumerated by Ó Conchubhair in his study, because within the global context, it is certain that Ireland is facing a paradox which gathers two groups of people, one claiming that the Irish language is a barrier which does not reflect the needs of modern, inclusive Ireland, saying that it belongs to a by-gone era, and another group advocating the maintenance of the language as a part of their identity.

For these reasons, it is, therefore, necessary to take into account the influence of Gaelic on the grammatical and lexical structure of Irish English and observe the sociolinguistic history of the English language in Ireland, as the country became a place of contradictions where British colonies permanently left traces. Language, in particular, is the most basic, yet representative in a culture, depicted as a continuous fight for identity and an engine in the development of world Englishes. The first section of the article opens the discussion about Irish English, understood as the variety of English spoken in Ireland over the years (including today). The term is employed in accordance with Hickey's distinction which suggests that HibernoEnglish is a learned term from Latin Hibernia "Ireland", but still used by specific authors such as Dolan $(2012,1998)$ and Filppula $(1993,1999)$. Irish English is the simplest term to use as it is parallel to other designations (American, Australian, Welsh English), and can be further differentiated where necessary. ${ }^{7}$ The paper will further investigate the complicated mosaic of influences observed at the phonetic

\footnotetext{
5 lbid., 227.

${ }^{6}$ Ibid., 230.

7 Raymond Hickey, Irish English. History and Present-Day Forms. (Cambridge: Cambridge UP, 2007), 162.
} 
level, irregularities in the morphology and syntax, the predisposition of the learners to use grammar in a specific mode and patterns specific to the native language. As such, an analysis of the language cannot be separated from an investigation of the land affected by these changes, therefore the second part of the article questions the remaining speakers of Irish, investigating issues that are tied to the use of language and construction of identity, as motivating factors for maintaining or not the language alive, questioning as well the situation over the past couple of decades, and seeking to see whether there could be formulated optimistic prospects for the future of the Irish language.

\section{New Perspectives on Irish English}

The English spoken in Ireland, known as Irish English presents numerous distinctive features in comparison with other forms of the language, such as American or British English. From a historical perspective, there are several interpretations that can be applied in terms of language continuity, however, the seventeenth century marks a crucial point. As such, the second half of the sixteenth century witnesses the plantations of Leix and Offaly under Queen Mary and of Munster under Elizabeth, followed by the defeat of the Irish rebels and their Spanish allies at the battle of Kinsale. ${ }^{8}$ The failures of the conflict from Ulster and the flight of Earls in 1607 led to invasions of English and Scottish settlers into the northern parts of Ireland, but the final, or the most influential change came in the 1650 s with the Cromwellian Settlement, which in Filppula's words "gave a strong impulse to the diffusion of the English language, ${ }^{9}$ " in numerous provinces, where landowners were English speakers and the servants and tenants had to learn the language.

Over the years, the continuous process of integrating the language in the Irish speaking communities has had visible results in the loss of its local features. At the same time, once Ireland was subjected to the process of colonialization which announced the existence of an unconscious wish within the citizens to maintain a level of linguistic distinctiveness vis-'a-vis the varieties of the former colonizing country, it became less regionally bound. As structured by Hickey in Irish English: History and present-day forms, the history of English in Ireland shows that there were multiple factors contributing to the construction of what today is Irish English:

\footnotetext{
8 Markku Filppula, The Grammar of Irish English. Language in Hibernian Style (London-New York: Routledge, 1999), 6.

9 lbid., 7.
} 
there was not only (i) internal change within the English brought to the country as of the late twelfth century and (ii) influence from Irish during the long period of language shift from the seventeenth through to the nineteenth century, but also (iii) a large degree of superimposition or adoption of more standard forms of English due to considerable exposure to forms of British English. This superimposition has led to layering in Irish English: remnants of former distributions, such as the presence of upshifted ME / [ $\varepsilon:]$ or / u / /e (unrounded, unlowered /u/), have become confined to certain registers and/or are indicative of strongly localized varieties ${ }^{10}$ (such as those in Dublin).

Along with social and sociological aspects of Irish English one particular aspect that opens the discussion is reflected in the particularities of the grammar which, as Filppula suggests, have "a unique combination of elements drawn from the two principal partners in the contact situation, English and Irish. ${ }^{11 "}$ Since this variety is characterized through flexibility which differs from a region to another, Hickey further emphasizes that in local forms of Irish English, both urban and rural, the distinction between short vowels before the historic/r/ (e.g. term [teım] and turn [teım]), in the supraregional variety, are represented in both cases through a single vowel, a rhotacised schwa. In Ireland, and perhaps in other European countries, "the main trigger for supraregionalisation was the introduction of general schooling and the rise of a native middle class during the nineteenth century. ${ }^{12 "}$ Within several Gaeltacht communities, the linguistic particularities are the results of their location, mainly due to their proximity to urban centres which encouraged movements towards the suburban settlements, so that numerous citizens of non-Gaeltacht origin moved into those areas. Though some of them are familiar with the Irish language, many of them do not use it on a daily basis. It is notable, however, that the number of English-speaking young parents increases. ${ }^{13}$ At the same, the evidence shows that the changes in grammar start among school-going children where they are familiarized from a young age with the English language and it seems that the Gaeltacht schools are faced with the daunting challenge of providing education for bilingual students whose ability to learn and use correctly the language, is compromised. Moreover, if it is to analyse how adults from rural areas (from

\footnotetext{
10 Hickey, Irish English, 309.

11 Filppula, The Grammar, 283.

12 Hickey, Irish English, 310.

${ }^{13}$ As suggested by Ó Giollagáin and Donnacha in A New View of the Irish Language, once "the proportion of English-speaking young parent increases, their influence impacts more significantly not just on the proportion of the Irish-speakers in their own age cohorts, but on the proportion of Irish-speakers in future Gaeltacht generations as well" (110).
} 
seventeenth and eighteenth centuries) became bilingual, the majority learned the language through direct contact with English speakers, meaning that the language was acquired in an unguided manner which had visible consequences for the grammar of the Irish English.

The intact preservation of the English language was a topic carefully planned, as the colonizers were afraid of the possible cultural changes between the two countries. They tried to limit the contact with the host territory not only in terms of the Irish language use but also in terms of wearing traditional apparel or riding on a saddle in the English fashion. The change involved pressure on the colonizers on the one hand, as they had to preserve what was theirs, but on the other hand, the greatest change took place among the Irish people who faced violence and coercion, as they were trying to maintain identity. Since one goal of colonialism was to lead the Empire into a position of supremacy, it is notable that the colonized territory was perceived as inferior, from the language to the culture and oftentimes including the character of the colonized, depicted as barbaric or savage. ${ }^{14}$ In fact, the British Empire was aware of these characteristics and they knew they had to control the language and the mind of the speakers. For instance, in Article III of the Statutes of Kilkenny issued in 1366, which Hardiman mentions in his study, there are emphasized the same suggestions,

\begin{abstract}
III. Also, it is ordained and established, that every Englishman do use the English language, and be named by an English name, leaving off entirely the manner of naming used by the Irish; and that every Englishman use the English custom, fashion, mode of riding and apparel, according to his estate; and if any English, or Irish living amongst the English, use the Irish language amongst themselves, contrary to the ordinance, and thereof be attainted, his lands and tenements, if he have any, shall be seized into the hands of his immediate lord, until he shall come to one of the places of our lord the king, and find sufficient surety to adopt and use the English language, and then he shall have restitution of his said lands or tenements, his body shall be taken by any of the officers of our lord the king, and committed to the next gaol, there to remain until he, or some other in his name, shall find
\end{abstract}

\footnotetext{
14 In 1588, Francisco de Cuellar sailed with the Spanish Armada and was wrecked on the coast of Ireland. He recognized that the locals were hospitable, but it seems that they were liked because, as he claims, "we came against (to oppose) the heretics, and were such great enemies of theirs; and if it had not been for those who guarded us as their own persons, not one of us would have been left alive. We had goodwill to them for this, although they were the first to rob us and strip to the skin those who came alive to land." He concluded: "In this country there is neither justice or right, and everybody does what he likes" (Kilfeather, p. 83).
} 
sufficient surety in the manner aforesaid: And that no Englishman who shall have the value of one hundred pounds of land or of rent by the year, shall ride otherwise than on a saddle in the English fashion; and he that shall do to the contrary, and shall be thereof attainted, his horse shall be forfeited to our lord the king, and his body shall be committed to prison, until he pay a fine according to the king's pleasure for the contempt aforesaid; and also, that beneficed persons of holy Church, living amongst the English, shall have the issues of their benefices until they use the English language in the manner aforesaid; and they shall have respite in order to learn the English language, and to provide saddles, between this and the feast of Saint Michael next coming. ${ }^{15}$

Until the seventeenth century when the English victory at the battle of Kinsale in 1601 causes the Flight of the Earls, these idealistic notes were meant to guide the colonizers, albeit the reality shows that the Statutes were ineffectual. The attitude of the Irish people was ambivalent, as on the one hand, the English language opened the potential of developing the commerce and infrastructure, but on the other hand, their culture was affected. At present, in comparison to other varieties of English, but most importantly in comparison to versions spoken in Britain, one outstanding difference lays in the pronunciation, which, as Dolan suggests, is similar to the one of the English language in its earlier forms, as meat is pronounced like mate, whilst consonants and vowels are removed and replaced by Irish vowels. Another case would be the consonants 'th' in a word such as thought pronounced as [t], thus making it sound like taught. ${ }^{16}$ On the other hand, grammar is particularly different, and as Gunnel Melchers and Philip Shaw have pointed out in World Englishes: An Introduction, several of the main characteristics are:

1. Like Scottish English, Irish English has unmarked plurality in nouns indicating measure, time, etc. in cases such as "two mile" or "five year."

2. A direct borrowing from the traditional Irish Language is the use of after in noun phrases such as "I'm only after my dinner."

\footnotetext{
15 See James Hardiman, A Statute of the Fortieth Year of King Edward III., Enacted in a Parliament Held in Kilkenny, A. D. 1367, before Lionel Duke of Clarence, Lord Lieutenant of Ireland (Victoria: Leopold Classic Library, 2015), 11.

16 Dolan Terence, Interview by Carolina P. Amador-Moreno. "How the Irish Speak English: A Conversation with T.P. Dolan," Journal of Irish Studies, 15 March 2007, para 3.
} 
3. Another characteristic of Irish English is nominalization, adding next to a word or a phrase which it does not generally have, as in "If I had the doing of it again, I'd do it different."

4. Like Scottish English, Irish English uses progressive forms of stative verbs, as in "I was knowing your face."

5. Irish English makes an explicit distinction between singular you/ye and plural youse (also found in other varieties such as AmE and AusE): "So I said to our Jill and our Mary: 'Youse wash the dishes'"

6. Another salient feature is the tendency to represent the logical subject of a sentence by a noun phrase governed by a preposition, as in "The money is with them" meaning "They have plenty of money." ${ }^{17}$

As it can be seen, Irish English offers significant particularities in comparison to other forms of English. Despite the relatively small territory, Ireland displays a mosaic of influences and a rich dialectal diversity. Scholars have analysed that from Dublin, Cavan and Donegal to Mayo or Limerick there is a significant contrast. At the linguistic level (syntax, vocabulary, idioms, pronunciation) the form of the English language reflects the influence of the Irish language, therefore, a case such as Galway's Gaeltacht and its distance from Dublin and Ulster means that the influence is stronger in the first case. From the Belfast Agreement of 1998, it is known that the committee promised to revise "the importance of respect, understanding and tolerance in relation to linguistic diversity," including the Irish language and other languages. At the same time, the British government promised to "take resolute action to promote the language," so that the linguistic differences and diversity present in the country will tolerate one another. The diversity of Irish English dialects can be divided into three main categories: Northern Irish English, Southern Irish English and the new Dublin English. For these reasons, the following examples will take into account two different communities: Galway, with an emphasis on the district Bóthar Mór, where Irish had a more visible impact on the English language, and Dublin, the place that has been the centre of politics and culture from the earliest days of English settlement.

17 Melchers Gunnel, Shaw Philip, eds. World Englishes (Stockholm: Hodder Education, 2011), 77-78. 
Over the past century, Galway city has experienced significant growth of the English-speaking population. The information from the 2016 census shows that the city has a population of 79,934, with an increase of almost 4,000 over the 2011 figures, which proves that in comparison to the majority of the previous censuses the population is continuously increasing. This growth of population over the years has developed the urban areas and it has diversified the communities and the villages. When the English language became more used within the area, the Irish language was still spoken (especially among older generations) especially in Bóthar Mór district where citizens declared themselves speakers of the Irish language in the 2002 census, though only $5,4 \%$ said that they regularly speak the language. ${ }^{18}$ Arne Peters suggests that the population of the community was and continues to be preponderant of lower and upper-class background, describing it as one of the wealthiest districts of Galway city. ${ }^{19}$ She further analyses based on a series of interviews from four generationally stratified female speakers, three salient phonological variables in the English of Bóthar Mór, seeking to observe the vowel and consonantal features of the language. For example, the raising of $/ \mathrm{e} /$ to $/ \mathrm{i} /$ preceding a nasal consonant is a well-studied feature of Irish English and it is present in this case too (e.g. send as sinned, pen as pin). Or the lowering of the open-mid back unrounded vowel $/ \Lambda$ to open back rounded vowel $/ \mathrm{b} /$ in words like up, some, lovely and country. The data does not reveal any innovation in the consonantal system, Irish English retaining the articulation of the post-vocalic/ $/ \lambda /$ in all positions, thus making rhoticity one of its main distinctive characteristics (e.g. beer and poor are realised as /bi: $\lambda$ / and /pu: / involving a stressed monophthong). In this case, the results suggest that the linguistic variation is conditioned by the social factor age and one factor that provides evidence for linguistic change which brings forward the younger speakers who opt for the interdental fricatives supporting claims that the language is undergoing a change in the direction of normative standardized varieties such as Standard British English. ${ }^{20}$

The English language has been present in Dublin for over 800 years, but the degree of consciousness of the language has not led to a term for it developing, therefore Dublin "contrasts with many large cities in England such as London with Cockney, Liverpool with Scouse and Newcastle with Georgie. ${ }^{21 "}$ When English settlers arrived in Dublin they realized quickly the importance of the place for the government of the country and they were interested in populating it shortly after their arrival. The city has clear divisions between high and low prestige, or between

18 Migge Bettina, Ní Chiosáin Máire, eds. New Perspective on Irish English (AmsterdamPhiladelphia: John Benjamin's Publishing Company, 2012), 32.

19 Ibid., 32.

20 Ibid., 43.

${ }^{21}$ Raymond Hickey, Irish English. History and Present-Day Forms (Cambridge: Cambridge UP, 2007), 151. 
the north and the south (the latter, for instance, is considered a special place for people who are looking for a home). As for grammar, Hickey suggests that among the most important particularities are: the centralization of the /as/ diphthong (e.g., time [tərm] - [təjəm]); the fronting of /au/ (e.g., down [dæun] - [dعun]); the overlong realization of phonemically long vowels (e.g., school [sku:əl]), the realization of historically short vowels before /r/ (e.g. circle first $[\mathrm{fu}:(\iota) \mathrm{s}(\mathrm{t})]$ ) and that of Early Modern English short /u/ (e.g. Dublin ['dublən]). ${ }^{22 " \prime}$

This brief analysis of some of the most important particularities of Irish English has proven that, over the years, the two languages merged and a clear union has formed between them. Despite the fact that this analysis has presented the form of the language up until the present moment, the great increase in immigration into Ireland continues, meaning that there are more and more numbers of people for whom English in Ireland is a second language, which perhaps will lead to new changes both in pronunciation and grammar. As exemplified above, Irish English is the result of a long process, of subversion in the process of maintaining identity. Despite the fact that the identity has been transformed over the years, alongside the emergence of the new version, Irish English will continue to embody the trace of the contact between colonizer and colonized.

\section{III. "We have to make a bigger noise to keep Irish": Maintaining Language and Identity}

The results were clear, "within relatively few years" the Irish language would cease to exist. These were the words uttered on everyone's lips when the results of the 1871 census were made known. However, some years after, in 2007, the Irish language became the twenty-third officially recognized language of the European Union. Is the Irish language still important? In a video in which several people from the streets of Galway were asked the same question the majority of the responses could be translated into one single word - hope - there is still hope for the revival of the language, as more and more people seem to become aware of its importance, of the fact that it is not enough to be able to have a basic conversation, but that something more than this should be done. Taking heed of these particularities, this section of the paper explores issues that are tied to the use of language and construction of identity, perceived as motivating factors for maintaining or not the language alive, questioning as well the situation over the past couple of decades, and seeking to see whether there could be formulated optimistic prospects for the future of the Irish language.

To define the premise of this analysis, it is necessary to mention the following quote which belongs to Patrick Pearse, a teacher, poet, writer, nationalist, who became one of the leaders of the Easter Rising in 1916, known as the

22 Ibid. 
embodiment of the rebellion, and whose thoughts are meant to awaken in the souls of those who know themselves as Irish the importance of keeping alive the mother tongue,

Now, if Ireland were to lose her language - which is, remember, an essential of her nationality -there might be conceivably me a free state in Ireland at some future date; but that state would not be the Irish nation, for it would have parted from the body of traditions which constitute Irish nationality. ${ }^{23}$

As noted in the above reaction, without the Irish language, the country can be considered a free state in the future, but the country would not be related to what once was defined as the Irish nation, it would have no soul, as it would lose its origins, its traditions which were supposed to form the base of Irish nationality. The subtle reaction could awaken in the souls of the citizens a desire to fight against the current when realizing that losing their language will metaphorically imprison them, and would alienate them from their culture.

First of all, the language maintains symbolic cultural importance due to the continuous promotional activities realized by the state since 1922, as well as the acceptance of the Irish language as "the national language, even though it is not widely spoken. ${ }^{24 "}$ Despite the fact that the language has been accepted as national, the reality contests the fact that Irish, though, spoken, it is still a minoritised language, present mainly in the small pockets of the Gaeltacht, in those patches of land representing places of the language "historical heartland, ${ }^{25}$ " as well as loose speakers around the country, people that are able, as those from the interview mentioned in the beginning, to keep a basic conversation. The language shift to English is still a threat as it continues to make its way in the Gaeltacht, and for this reason, scholars tend to say that the language has been predicted. Moreover, amongst the most significant factors stands the existence of the sustainable Irishspeaking communities beyond the Gaeltacht. This is understood as a sociological, necessary fact for the continuity of the Irish language while at the same time inviting the redefinition of the Gaeltacht. ${ }^{26}$ Along with the role of the Gaeltacht, it could be further mentioned the legislation of the Irish language, the one for instance from

23 See Patrick Pearse. "Commentary", Retrieved from Ricorso, www.ricorso.net/rx/az data/authors/p/Pearse_P/comm.htm.

24 See John Walsh. "The Irish language and contemporary Irish identity," Irish Identities: Sociolinguistic Perspectives, Raymond Hickey, Carolina P., eds. (Amador-Moreno: De Gruyter Mouton, 2020), 22.

$25 \mathrm{Ibid}$.

${ }^{26}$ Diarmait Mac, Giolla Chríost, The Irish Language in Ireland (From Goídel to Globalisation. Abingdon: Routledge, 2005), 175. 
1998, namely the Good Friday Agreement which contained significant promises with regards to the language maintenance, such as the intention to encourage and facilitate Irish-medium education in line with current provision for integrated education; to explore urgently with the relevant British authorities, and in cooperation with the Irish broadcasting authorities, the scope for achieving more widespread availability of Teilifis na Gaeilige in Northern Ireland; to seek more effective ways to encourage and provide financial support for Irish language film and television production in Northern Ireland, as well as to encourage the parties to secure the agreement that this commitment will be sustained by a new Assembly in a way which takes care about the desires and sensitivities of the community. Just as Ó Gadhra suggests, "in the modern world there is a 'critical mass' for language 'viability', especially exercised by those communities when confronted with massive Anglo-American commercial 'standardization'. ${ }^{27 "}$

What is certain, however, is that in order to maintain the Irish language alive, to preserve the Gaeltacht communities and to respect the idealistic perspective of the legislation, special attention and careful planning should be taken into consideration. In fact, the ardent desire to maintain the language should not only be tied to the inner drive to preserve identity, but rather it should be the result of constant work. In this sense, not only the National Government can take action, but also, and more important would be to involve the education system (such as the Gaelscoil), Church, family, the main forces behind the development of future generations, who have the responsibility to form others from a young age. In this sense, special attention must be offered to younger generations, that once enrolled in a primary school should have the possibility to understand the importance of Irish and learn it.

On the other hand, the country has a long history in the debate between language, identity and nationalism, amplified, as mentioned earlier by the statebuilding project and the constant work coming from education and media. However, there are voices that underline the centrality of language to identity and claim that if the language will be lost, "there would be little discussion about identity in the Republic. ${ }^{28}$ " In fact, during the period of transition, the cultural and political nationalism that defined Irish public life was a key marker of an independent Irish identity "precisely because of its decline over the previous two centuries. ${ }^{29 "}$ Despite the fact that the government granted specific protections to Irish communities, Irish became an emblem of identity but in a symbolical way, or as Walsh suggests,

27 Gadhra, Nollaig Ó. "What Future for the Irish Gaeltacht Communities in the Twenty-First Century?" Proceedings of the Harvard Celtic Colloquium 24/25 (2004): 73-85. Accessed July 23, 2021: http://www.jstor.org/stable/40285182.

28 John Walsh, "The Irish language and contemporary Irish identity", 25.

29 Ibid. 
Although the paradigm was based on the ideology of 'one-nation, one-language', the Irish situation was complicated by the overwhelming dominance of English following rapid language shift in the eighteenth and nineteenth centuries but the aim, at the level of rhetoric in any case, was to restore Irish to its pre-eminent position as the vernacular. ${ }^{30}$

A relevant example in this sense is the case of Northern Ireland where speaking the language became rather a form of protest against the union with the UK. In the North of the country, the Irish language has known several changes over the years. However, despite the efforts made by the community (such as the primary school Bunscoil Phobal Feirste), those involved suffered from a lack of support as they were often seen with suspicion, able to threaten Northern Ireland's position within the United Kingdom. ${ }^{31}$ In the 1990s the situation of the Irish language began to improve when authorities from Wales and Scotland offered financial support. In this sense, results can be observed in the Census from 1991 when for the first time it was included a question regarding the use of the language, which stated that over 142,000 , or over $9 \%$ of the population had some knowledge of Irish. ${ }^{32}$ Though 9,4\% stated that they speak Irish, it cannot be assumed with certainty that they are fluent in the language, and just as in the video footage mentioned at the beginning, people were, and still are, willing to portray themselves as Irish speakers.

If we were to make a comparison between the all-Ireland survey from 20001 , and the one from 2013, some interesting aspects will be brought up - aspects that could be used to construct an overall image of the language. Besides the fact that the survey was administered for the first time in Northern Ireland, compared with earlier surveys there was a significant reduction in the percentage of those who agreed with the statement that "without Irish, Ireland would certainly lose its identity as a separate culture" (from $60 \%$ in 1993 to $41 \%$ in 2001), whereas in the allIreland survey from 2013, the association between the Irish language and identity was much stronger in the Republic than in Northern Ireland, and almost 2 in 3 respondents, meaning $64 \%$ in the Republic agreed with the statement that "without Irish, the Republic of Ireland would lose its identity as a separate culture," and most importantly only 1 in 3, meaning $33 \%$ of Northern respondents agreed that Irish was a fundamental part of their identity.

In relation to the results of the surveys exemplified above, it is necessary to mention another example that provides concrete information on how the language

\footnotetext{
$30 \mathrm{Ibid}$.

31 McDermott Philip, "Irish isn't spoken here?" in Language policy and planning in Ireland. English Today, (2011): 27-28.

32 Ibid., 29.
} 
is manifested in public speaking, namely the new media ventures which seem to "represent the increasingly dynamic presence of the Irish language in the public life of Ireland, ${ }^{33 "}$ mainly television (e.g. Teilifis na Gaelige, the new daily Irish-language television service), and the new weekly Irish newspaper Foinse, that reflect "positive intentions and achievement in a socio-economic climate that is negative and threatening. ${ }^{34 \prime}$ Despite the fierce competition with other televisions offering services in English, the results showed that the Marketing of TnG was fairly efficient as it turned out to have a viewing audience of 180.000 , a respectable number in comparison to other TV services. Nonetheless, if it is to take one optimistic prospect from here, it will include the continuous tension and competition between the two languages, and it will refer to the community which will have to be, as mentioned earlier, as much as possible educated and interested in understanding their rights, history, identity.

Drawing on from previous examples, and from Walsh's finely researched article, when speaking about identity among new speakers of Irish one can divide the analysis in two main strands, the first one encompasses identity as a motivation for becoming a new speaker, and the second one takes into consideration identity positions of new speakers. The first category, "Cultural nationalism," exemplifies motivation as a factor specific to older speakers due in part to the dominance of such discourses, at least until the 1960s, and it can be observed in a case such as Edel's, who became ashamed at the age of 11 , when he realized that he was speaking "another language of another country," or Niamh who became familiar with the language whilst being a student - both experiences emphasizing, therefore "the importance of Irish in familiar nationalist terms, including tropes of the duty to speak Irish. ${ }^{35 "}$ The second motivating factor is the Gaeltacht, the community where Colm found "freedom" in contrast to the repressive atmosphere of the North during the Troubles. On the other hand, the identity positions of new speakers can be classified into three main strands, the first one mentions the primary Irish-speaking identity, focusing on identity as motivation for learning the language; the second one is the ambiguous or mixed identity, describing someone who was raised speaking English in the Gaeltacht but who had Irish speaking relatives; and the third, and final category which includes the primary Irish-speaking identity, namely those citizens brought up with Irish only and learned Irish at school, before gaining fluency at university.

Before moving on to formulate the final remarks, in what follows it is necessary to point out larflaith Watson's argument found in her article titled "The Irish Language and Identity", included in A view of the Irish Language, where she

33 Further information can be found in Blake James J., "The Enhanced Public Presence of Irish," New Hibernia Review / Iris Éireannach Nua 1, no. 2 (1997): 152-56. Accessed July 23, 2021: http://www.jstor.org/stable/20557407.

34 Ibid., 152.

35 John Walsh, "The Irish language and contemporary Irish identity," 34-40. 
suggests that in more recent years there has been a shift toward a more neoliberal ideology in which Ireland flows with the currents of globalization. ${ }^{36}$ Over the past decade, in this ideology, it can be observed an individualization, such as tax individualization, depicted as rational and which perfectly aligns in what should be described as a new approach to the Irish language where learning and speaking Irish is "a 'rational' choice made by individuals. ${ }^{37 "}$ " Furthermore, this new approach is encouraged in the Official Languages Act 2003, whose purpose is to implement the use of the language for official purposes in the state and administrative systems. At the same time, the continuous implications to maintain the language alive reflects "wider ideological processes," but the national identity has remained at the core of the efforts for reviving the Irish language.

Such an analysis provides a realistic perspective of the status of the Irish language and demonstrate at the same time that identity, with its two major motivating factors, cultural nationalism and the Gaeltacht, is at the heart of maintaining the functionality of the language. The analysis began by emphasizing the importance of the Irish language as a defining feature of the Irish nation and as part of the traditions that constitute the country. From here, it was analysed the symbolic role of the language and mentioned the necessary plan in order to respect the promises from the Good Friday Agreement, followed by comparisons between all-Ireland surveys and future prospects of the language, therefore, it will be interesting to see if in the near future the relationship between the Irish language, culture and national identity continue to change gradually, or if we will assist to a redefinition of these three components.

\section{Conclusion}

In the mosaic of World Englishes, Irish English occupies its own place. In connection with identity, this version of English has emerged as a result of subversion of English, of the relationship between the colonizers and the colonized. Nowadays, this context is still a factor that influences and leaves traces on the language, as the number of immigrants increases, so there are more and more people for whom English is a second language, fact which in the near future will lead to new changes in pronunciation and grammar. At the same time, Irish English analysed alongside the still existent hope of the citizens to preserve Irish, manages to further emphasize a necessary point of view coming from those citizens for whom the mother tongue must be maintained not only as a symbol of national identity but also as a definition of the soul, origins and traditions of the country. This analysis has further emphasized the clear profile of grammar and

\footnotetext{
${ }^{36}$ Pháidín and Ó Cearnaigh, A New View of the Irish Language, 73.

37 Ibid. 74
} 
vocabulary, concluding therefore that contemporary Ireland, similar to other countries from Europe or the rest of the world, is experiencing waves of immigrants who bring with them new cultures that on a long term will change the current features of the language. 